\title{
Heat-insulating materials in modern building industry
}

\author{
Kyrylo Plakhotnikov ${ }^{1}$, Dmitry Bondarenko ${ }^{1}$, Elena Dedenyova ${ }^{1}$, Medeia Saliia ${ }^{1, *}$, and \\ Tatiana Kostuk ${ }^{1}$ \\ ${ }^{1}$ Kharkiv National University of Civil Engineering and Architecture, 61002 Sumska st, 40, Kharkiv, \\ Ukraine
}

\begin{abstract}
The characteristic feature of the modern construction industry is the broad appliance of contemporary design and technology solutions, which require new constructive, water-proof, finishing and heat-insulating materials. Implementation of new energy saving norms for the residential sector and increasing requirements for thermal protection of buildings have sharpened an issue how to develop new thermal insulation materials. Although the thick-layered heat insulation is known for a while, the heat insulation made of thin layers requires additional studies. This group of constructive materials is relatively new; there is no equipment and techniques for studying that. The structure of these materials is composite, comprising hollow ceramic and glass microspheres and a binder substance. This combination lends the lightness to the material and makes it highly adhesive to a surface where it should be applied. After application to a surface, the microspheres create a multilayered combination, reflecting up to $80 \%$ of heat stream. It makes the premises more comfortable, cutting down the expenditures on heating in winter, and summer air conditioning as well.
\end{abstract}

\section{Introduction}

The demand for the thermal insulating materials is growing routinely. Ever more manufacturers offer various materials, such as mineral cotton, foam plastic, liquid heat insulation [1-4]. One of the reasons of high interest to the liquid heat insulation is low labor input of ventilated front mounting, and the problem of heat insulation in old houses which have complex configurations of facades and require restoration. After application of the heat insulating composition to outer or inner walls and ceilings, the values of heat egress and heat ingress by a frame filling lowered. The methods for determination of its properties are to be elaborated $[5,7,8]$.

\section{Materials and methods}

As an outcome of the studies, the heat insulation composition was obtained. It comprises white portland cement, hollow microspheres of glass and aluminosilicate with diameters

\footnotetext{
*Corresponding author: medeasalia@gmail.com
} 
ranging from 5 to $30 \mu \mathrm{m}$, and the chemical complex additive (CCA) for regulation of hydration processes and strength enhancement. Furthermore, an additive of methylcellulose (MC) is merged into the composition for correction of its rheological properties, to enhance adhesion to the concrete surface and other stone-like bases. The concrete base was chosen for studies of the adhesive strength of the heat insulating thin-layered coating. The application of the thin-layered coating was performed by a paint brush. In order to provide the compression strength studies, the samples $4 \times 4 \times 8 \mathrm{~cm}$ were produced and cut into cubes before the tests. The samples are shown in Fig.1.

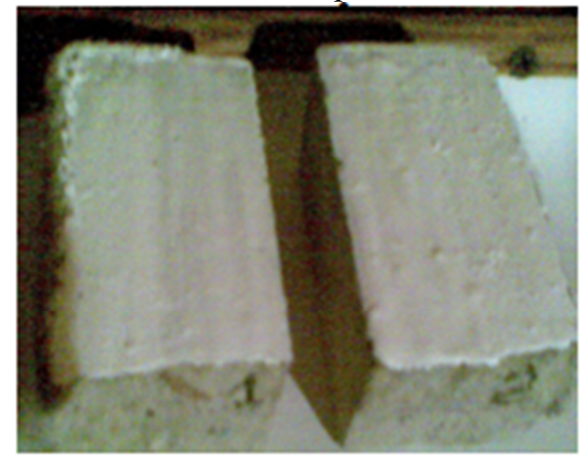

a)

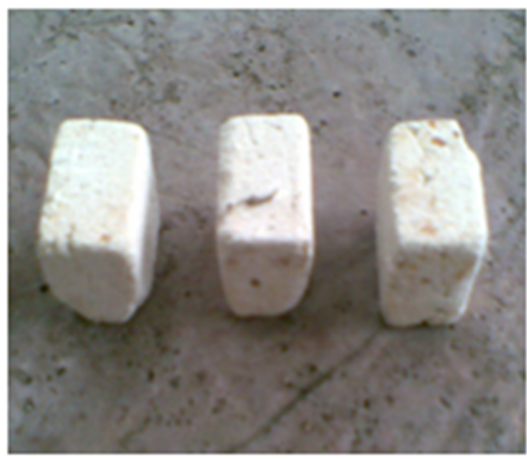

b)

Fig. 1. Pictures of the samples for experimental determination of: $a$ - adhesive strength, $b-$ compressive strength.

The adhesive strength of this coating was defined by the pull-off method, as a function of the concentration of methylcellulose $[6,9,10]$. The results of the studies of adhesive strength in the coating based on aluminosilicate and glass hollow microspheres are presented in fig.2. The diagram shows, that the maximal adhesive strength of the coating based on hollow microspheres corresponds to the concentration of MC $0.25-0.3 \%$ and comprises 1.2-1.4 MPa. It meets the normative requirements to the cement-based coatings, DSTU B.V.2.7-126:2011 "Mixtures constructive, dry, and modified. General technical requirements".

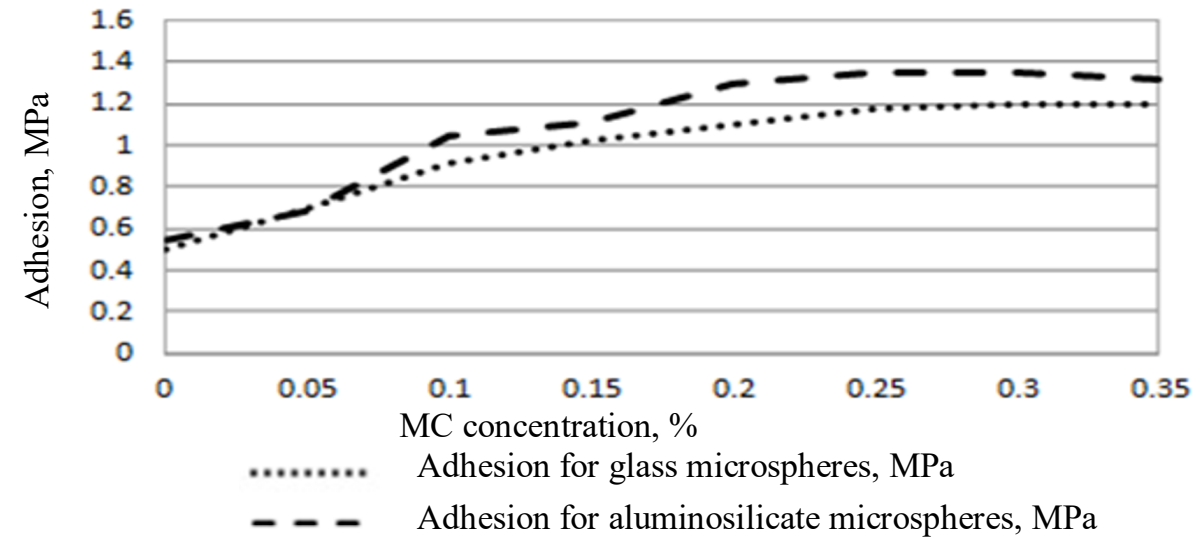

Fig. 2. The results of adhesive strength tests performed by the pull-off method in samples of coatings, as a function of MC concentration.

Also, the strength in compression for the samples of compositions, containing glass and aluminosilicate microspheres, was determined, see fig. 3 . 


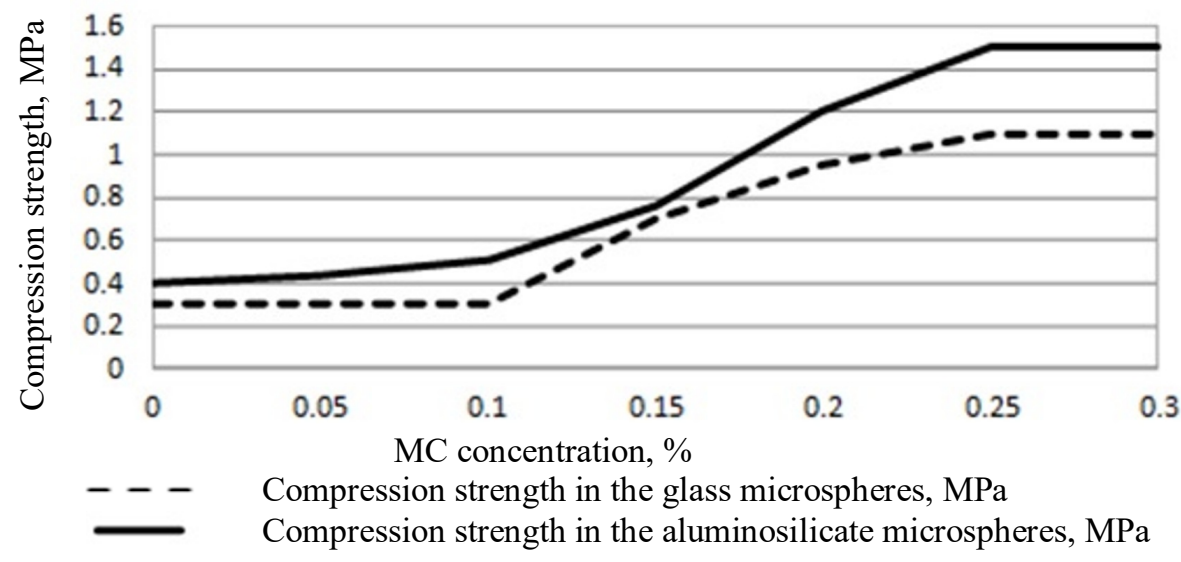

Fig. 3. The test results for the compression strength limit on the $28^{\text {th }}$ day in the samples of the coating composition as a function of $\mathrm{MC}$ concentration.

Fig. 3 shows, that the highest values of strength are found in the composites where the values of $\mathrm{MC}$ concentration comprise $0.25-0.30 \%$. Among them, the maximal value is shown for the composites based on the aluminosilicate hollow microspheres. On the grounds of the results, we obtained the samples of the compositions of heat insulating coatings with aluminosilicate and glass microspheres and fixed $0.25 \% \mathrm{MC}$ concentration. Meanwhile, the concentration of CCA added to the composition for intensification of the hydration processes was variable. The results of the experiment are presented in fig.4.

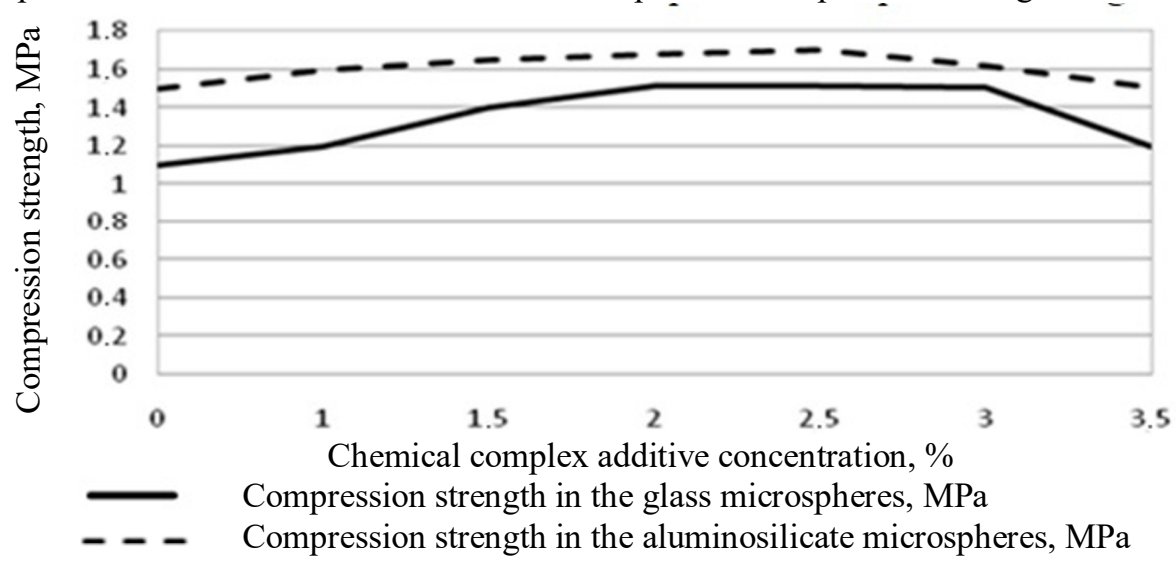

Fig. 4. The results of the compression strength limit test carried out on the $28^{\text {th }}$ day in the samples of the coating composition as a function of CCA concentration.

Fig. 4 shows, that the composites containing the aluminosilicate microspheres have the highest strength, and the optimal amount of the additive is $2-3 \%$.

Out of the composites, which were optimal in terms of the methylcellulose concentration and the CCA concentration, the heat insulating coatings were produced and then applied to $1 \mathrm{~mm}$ thick concrete slabs. The slabs were placed on stands open-air for testing in natural conditions (Fig.5). The coatings were checked every 3 days by a $4 x$ magnifier. 


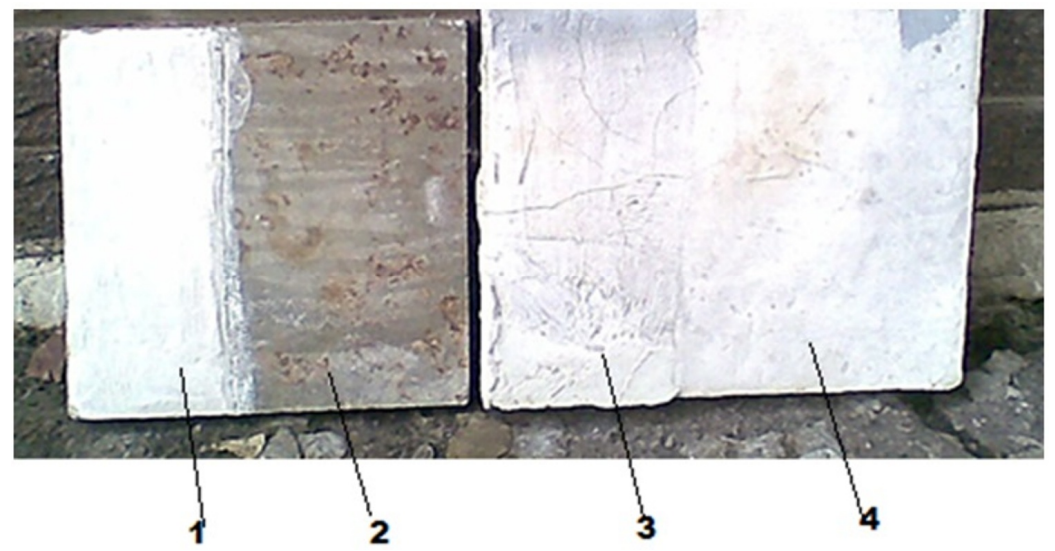

Fig. 5. Testing the heat insulating covers in natural conditions: 1 - aluminosilicate microspheres based coating; 2 - a concrete slab; 3 - a concrete slab; 4 - glass microspheres based cover.

Observation of the heat insulating coatings in natural conditions during 12 months has shown that the surfaces remain without any changes; no cracks, delaminations, or distentions have been found.

\section{Conclusions}

The cement compositions for thin layered heat insulation based on the hollow microspheres of aluminosilicate and glass, which have been obtained in result of the studies, have the good adhesive strength to concrete bases, and the compression strength, that allows the coating to preserve its integrity and weather resistance.

\section{References}

1. B.M. Shoykhet. The constructive materials. New quality and nomenclature of the heat insulating materials Saint Gobain Isover, 3, 19-21 (2005)

2. Yu.G. Skrypnyk, V.V. Petrovych, T.V. Skrypnyk. Building Industry of Ukraine. Foam polystyrene as a reality of today, 6, 37-39 (2002)

3. R.I. Burangulov, G.V. Tenenbaum, D.M. Khabirov. The constructive materials. The technology of obtaining and application of superlight and light polystyrene foam concrete mixtures, 12, 16-17 (2003)

4. The constructive materials. Heat insulating items URSA GLASSWOOL, 5, 38-39 (2005)

5. M. Tchaika. Heat insulating paints as an effective way of saving energy sources. http://naukarus.com/teploizolyatsionnye-kraski-effektivnyy-sposob-ekonomiienergoresursov

6. A.S. Inozemtsev, E.V. Korolev. Industrial and civil construction: a journal. Hollow microspheres - an effective filler for high-strength lightweight concrete, 10, 80-83 (2013)

7. Liquid thermal insulation ThermoRon facade. https://www.microspheres.com.ualen/ produktsiya/stroitelnaya-teploizolyatsiya/140-zhidkaya-teploizolyatsiya-termoronfasad

8. Aluminosilicate microsphere. https://en.wikipedia.org/wiki 
9. ISO 4624:2013. Paint materials. Pull-off test for adhesion

10. K.V. Plakhotnikov, O.I Dyomina O.I Bondarenko, O.B Dedenova. Scientific Bulletin of Construction. Effect of water-retaining additives on the adhesion strength of thinlayer heat-insulating coatings based on mineral binders, 1, 152-155 (Kharkiv, 2018) 